\title{
A study on knowledge regarding integrated management of neonatal and childhood illness among trained anganwadi workers of Surendranagar district, Gujarat, India
}

\author{
Krupal J. Joshi*, Hetal T. Koringa, Kishor M. Sochaliya , Girija P. Kartha
}

Department of Community Medicine, C. U. Shah Medical College \& Hospital, Surendranagar, Gujarat, India

Received: 31 December 2015

Revised: 04 January 2016

Accepted: 20 January 2016

\section{*Correspondence:}

Dr. Krupal J. Joshi,

E-mail: dr_krupal@yahoo.co.in

Copyright: () the author(s), publisher and licensee Medip Academy. This is an open-access article distributed under the terms of the Creative Commons Attribution Non-Commercial License, which permits unrestricted non-commercial use, distribution, and reproduction in any medium, provided the original work is properly cited.

\section{ABSTRACT}

Background: IMNCI guidelines are a simplified system of diagnosis and treatment designed for the use by health worker with limited training. The aim and objectives of the study was to study the level of awareness about the concept of IMNCI amongst trained AWWs and to assess the extent of knowledge and skills of the AWWs regarding the management after the training.

Methods: A cross sectional study conducted from August 2012 to January 2013. After enlisting all talukas of Surendranagar district, 5 talukas were selected through simple random sampling. Out of total 833 AWWs of these 5 talukas 774 were interviewed at monthly taluka meeting.

Results: Most of the anganwadi workers were of the age group 31 to 50 years and majority of them were educated up to secondary level (49.49\%). Half of the respondents (57.37\%) answered correctly about objectives of IMNCI. More than half $(55.5 \%)$ of the respondents did not know the assessment criteria of diarrheal illness. Only 3.3\% respondents knew that only in drawing of chest is a clinical feature of pneumonia. Nearly one third of the respondents i.e., $32.5 \%$ could be able to list out all the clinical features of malaria. Only $8.8 \%$ of the respondents could be able to identify grade 1 malnutrition. Only about $30.9 \%$ of the respondents correctly identified anemia in child using standard IMNCI guidelines.

Conclusions: There are many lacunae in the knowledge of AWWs in the various perspective of IMNCI; there is need for refresher course within short time period to sustain the knowledge of AWWs for success of IMNCI program.

Keywords: IMNCI, Anganwadi workers, Cross sectional study

\section{INTRODUCTION}

Low cost interventions could reduce neonatal mortality up to $70 \%$ if provided universally. Providing quality care to sick children in middle \& low-income countries including India is a difficult task. ${ }^{1}$

During the mid-1990s, the World Health Organization (WHO), in collaboration with UNICEF and many other agencies, institutions and individuals, responded to this challenge by developing a strategy known as the Integrated Management of Childhood Illness (IMCI). ${ }^{2}$ For
Indian version, IMCI was adapted as integrated management of neonatal and childhood illness (IMNCI). ${ }^{3}$

IMNCI aims to reduce death, illness and disability to promote improved growth and development among children under-five years of age and target acute respiratory infections (ARI), diarrhea, measles, malaria and malnutrition, which are the five main causes of childhood deaths. The IMNCI guidelines are a simplified system of diagnosis and treatment that is designed for the use by health worker with limited training and little or no lab support with this endeavor the present study has been 
conducted to know the knowledge among trained anganwadi workers. ${ }^{4}$

The aim and objectives of the study was to study the level of awareness about the concept of IMNCI amongst trained AWWs and to assess the extent of knowledge and skills of the AWWs regarding the management after the training.

\section{METHODS}

The present study was a cross sectional study conducted from August 2012 to January 2013. After enlisting all talukas of Surendranagar district, 5 talukas were selected through simple random sampling for the study. (Sayla, Limbdi, Dhranghdra, Muli and Wadhwan).

The study was done by using pretested semi structured proforma among all anganwadi workers of 5 talukas who have received basic IMNCI training. Out of 833 anganwadi workers 774 were interviewed at monthly taluka meeting and remaining 59 anganwadi workers were either absent during this meeting or submitted incomplete questionnaire.

\section{RESULTS}

Table 1 show that most of the anganwadi workers were of the age group 31 to 50 years and majority of them were educated up to secondary level (49.49\%).

Table 1: Age and education status of the anganwadi workers.

\begin{tabular}{|lll|}
\hline \multirow{2}{*}{ Age Group } & \multicolumn{2}{l|}{ No. of trained A WWs } \\
\hline $20-30$ & Number & Percentage \\
\hline $31-40$ & 108 & $13.94 \%$ \\
\hline $41-50$ & 275 & $35.53 \%$ \\
\hline $51-60$ & 268 & $34.63 \%$ \\
\hline Education status & 123 & $15.90 \%$ \\
\hline Primary & ----- & ---- \\
\hline Secondary & 153 & $19.76 \%$ \\
\hline Higher secondary & 383 & $49.49 \%$ \\
\hline Graduation and above & 138 & $17.83 \%$ \\
\hline Total & 100 & $12.92 \%$ \\
\hline & 774 & $100 \%$ \\
\hline
\end{tabular}

Nearly $20 \%$ of the workers were educated up to primary level which could act as a barrier to any program implementation (Table 1).

When the trained respondents were asked about the objectives of the IMNCI more than half of them $(57.37 \%)$ answered correctly about its objectives.

About $11.88 \%$ and $30.75 \%$ knew that training is to decrease the less than 5 mortality rate and neonatal mortality rate respectively (Table 2).
Table 2: Knowledge of respondents about the objectives of IMNCI.

\begin{tabular}{|lll|}
\hline Objectives of IMNCI & Frequency & Percentage \\
\hline $\begin{array}{l}\text { To decrease under 5 } \\
\text { mortality rate }\end{array}$ & 92 & $11.88 \%$ \\
\hline $\begin{array}{l}\text { To decrease neonatal } \\
\text { mortality rate }\end{array}$ & 238 & $30.75 \%$ \\
\hline Both of above & 444 & $57.37 \%$ \\
\hline Total & 774 & $100 \%$ \\
\hline
\end{tabular}

Regarding the knowledge of assessing the serious illness, $80.7 \%$ of anganwadi workers were correctly able to classify the illness by recognizing the three clinical signs of serious illness. About $9.6 \%$ and $9.7 \%$ respondents could classify the illness into no infection and mild infection respectively.

Table 3: Knowledge of anganwadi workers regarding the following questions (0- 2 months old child).

\begin{tabular}{|c|c|c|}
\hline Question & Frequency & Percentage \\
\hline $\begin{array}{l}\text { In } 0-2 \text { month's old baby } \\
\text { when there is convulsion, } \\
\text { increased respiratory rate, } \\
\text { and in drawing of chest, it is } \\
\text { a clinical feature of which? }\end{array}$ & --- & --- \\
\hline Mild infection & 75 & $9.7 \%$ \\
\hline No infection & 74 & $9.6 \%$ \\
\hline Probable severe infection & 625 & $80.7 \%$ \\
\hline $\begin{array}{l}\text { When do you give first } \\
\text { dose of Cotrimoxazole in } \\
0-2 \text { month's old child? }\end{array}$ & ---- & ---- \\
\hline Probable infection & 352 & $45.4 \%$ \\
\hline Severe diarrhea & 200 & $25.9 \%$ \\
\hline All of above & 222 & $28.7 \%$ \\
\hline $\begin{array}{l}\text { In } 0-2 \text { months old baby } \\
\text { suggestive of diarrhoea, } \\
\text { which examination do you } \\
\text { carry out }\end{array}$ & ---- & ---- \\
\hline $\begin{array}{l}\text { Look for consciousness } \\
\text { and general condition of } \\
\text { baby }\end{array}$ & 44 & $5.6 \%$ \\
\hline $\begin{array}{l}\text { Frequency of diarrhoea } \\
\text { and skin pinch }\end{array}$ & 314 & $40.6 \%$ \\
\hline Examination of eyes & 71 & $9.3 \%$ \\
\hline All of above & 345 & $55.5 \%$ \\
\hline $\begin{array}{l}\text { When } 0-2 \text { month is old baby } \\
\text { has difficulty in breast } \\
\text { feeding what you will do? }\end{array}$ & ---- & ---- \\
\hline Look for general condition & 21 & $2.71 \%$ \\
\hline Look for sucking of baby & 57 & $7.38 \%$ \\
\hline $\begin{array}{l}\text { Look whether baby is } \\
\text { properly attached to } \\
\text { mother or not }\end{array}$ & 175 & $22.60 \%$ \\
\hline All of above & 521 & $67.31 \%$ \\
\hline Total & 774 & $100 \%$ \\
\hline
\end{tabular}


Table 4: Knowledge of anganwadi workers regarding disease prevented by immunization in 0-5 year old child.

\begin{tabular}{|lll|}
\hline $\begin{array}{l}\text { Which disease can be } \\
\text { prevented by } \\
\text { immunization in children? }\end{array}$ & Frequency & Percentage \\
\hline Tuberculosis & 31 & $4 \%$ \\
\hline Polio & 33 & $4.3 \%$ \\
\hline Measles & 11 & $1.4 \%$ \\
\hline $\begin{array}{l}\text { Diphtheria, whooping } \\
\text { cough, tetanus }\end{array}$ & 38 & $4.9 \%$ \\
\hline All of above & 661 & $85.4 \%$ \\
\hline Total & 774 & $100 \%$ \\
\hline
\end{tabular}

When their knowledge was assessed regarding the administration of first dose of Cotrimoxazole in 0-2 month's old child, (Cotrimoxazole $80 \mathrm{mg}$ Trimethoprim and $400 \mathrm{mg}$ Sulphamethoxazole) $28.7 \%$ of respondents correctly answered when to give first dose of Cotrimoxazole.

Regarding their knowledge about clinical features of diarrhea, nearly half of them i.e. $44.5 \%$ correctly was able to identify all the clinical features of diarrhoeal illness and more than one third of respondents (40.6\%) believed that frequency of diarrhea and skin pinch are important clinical features. More than half $(55.5 \%)$ of the respondents did not know the assessment criteria of diarrheal illness. Remaining 5.6\% and $9.3 \%$ believed that general condition of baby and examination of eyes were important findings for the diarrhea respectively (Table 3).

When they were being inquired about knowledge related to breast feeding problems, about $67.31 \%$ of the respondents replied that they will look for general condition, sucking of baby and whether baby is properly attached to mother or not. However $22.60 \%$ respondents replied that they will look for whether baby is properly attached to mother or not and $2.71 \%$ replied that they will look for general condition (Table 3).

When they were asked about diseases which could be prevented by immunization, $85.4 \%$ of respondents could correctly name all the six disease (i.e. tuberculosis, polio, measles, diphtheria, whooping cough, tetanus) (Table 4).

When AWWs had been asked about the clinical features of pneumonia, $62.9 \%$ of respondents had mentioned all the clinical features. Only 3.3\% respondents knew that only in drawing of chest is a clinical feature of pneumonia.

Nearly one third of the respondents i.e., $32.5 \%$ could be able to list out all the clinical features of malaria and more than half of the subjects $(56.8 \%)$ believed that fever is the only presentation in case of malaria while $5.7 \%$ of respondents believed that convulsion in child is presentation of malaria (Table 5).
Table 5: Knowledge of anganwadi workers regarding the following questions ( 2 months-5 years old children).

\begin{tabular}{|c|c|c|}
\hline Questions & Frequency & Percentage \\
\hline $\begin{array}{l}\text { What are the clinical } \\
\text { features of pneumonia in } \\
2 \text { months to } 5 \text { years old } \\
\text { child? }\end{array}$ & ---- & ---- \\
\hline $\begin{array}{l}\text { Breathlessness and } \\
\text { increased respiratory rate }\end{array}$ & 193 & $24.9 \%$ \\
\hline In drawing of chest & 26 & $3.3 \%$ \\
\hline Cough & 69 & $8.9 \%$ \\
\hline All of above & 486 & $62.9 \%$ \\
\hline $\begin{array}{l}\text { What are the clinical } \\
\text { features of malaria in } 2 \\
\text { months to } 5 \text { year old } \\
\text { child? }\end{array}$ & --- & ---- \\
\hline Unconsciousness in child & 39 & $5 \%$ \\
\hline Convulsion in child & 44 & $5.7 \%$ \\
\hline Fever & 440 & $56.8 \%$ \\
\hline All of the above & 251 & $32.5 \%$ \\
\hline $\begin{array}{l}\text { What examination do you } \\
\text { carry in case of } 2 \text { month } \\
\text { to } 5 \text { year old child with } \\
\text { malnutrition? }\end{array}$ & --- & ---- \\
\hline $\begin{array}{l}\text { On examination child } \\
\text { seems to be malnourished }\end{array}$ & 123 & $15.9 \%$ \\
\hline $\begin{array}{l}\text { Examination for pedal } \\
\text { edema }\end{array}$ & 27 & $3.5 \%$ \\
\hline $\begin{array}{l}\text { To decide degree of } \\
\text { malnutrition from growth } \\
\text { chart }\end{array}$ & 275 & $35.6 \%$ \\
\hline All of the above & 349 & $45 \%$ \\
\hline $\begin{array}{l}\text { On the growth chart when } \\
\text { child marking of weight } \\
\text { for age is below the fourth } \\
\text { curve it's an indicator of? }\end{array}$ & ---- & ---- \\
\hline Grade 1 malnutrition & 68 & $8.8 \%$ \\
\hline Grade 2 malnutrition & 20 & $2.6 \%$ \\
\hline Grade 3 malnutrition & 62 & $8 \%$ \\
\hline Grade 4 malnutrition & 624 & $80.6 \%$ \\
\hline $\begin{array}{l}\text { According to IMNCI } \\
\text { training to diagnose } \\
\text { anaemia which } \\
\text { examination you will } \\
\text { carry out in child? }\end{array}$ & --- & ---- \\
\hline Examinations of eye & 125 & $16.1 \%$ \\
\hline Examination of tongue & 91 & $11.7 \%$ \\
\hline Examination of palm & 238 & $30.9 \%$ \\
\hline Examination of blood & 320 & $41.3 \%$ \\
\hline total & 774 & $100 \%$ \\
\hline
\end{tabular}

$45 \%$ of the respondents could be able to correctly mention all the task needed for the assessment of malnutrition while more than one third of the respondents i.e. $35.6 \%$ believed that plotting on growth chart is 
sufficient and minority of them (3.5\%) believed that examination of pedal edema is necessary (Table 5).

Majority i.e. $80.6 \%$ of the respondents correctly identified the grade 4 malnutrition from growth chart, while only $8.8 \%, 2.6 \%$ and $8 \%$ of the respondents could be able to identify grade 1, 2 and 3 malnutrition respectively (Table 5).

Table 6: Association between educational status of anganwadi workers and the need for refresher course.

\begin{tabular}{|llll|}
\hline $\begin{array}{l}\text { Educational } \\
\text { status }\end{array}$ & Yes & No & Total \\
\hline Primary & $118(77.1 \%)$ & $35(22.9 \%)$ & $153(100 \%)$ \\
\hline Secondary & $282(73.6 \%)$ & $101(26.4 \%)$ & $383(100 \%)$ \\
\hline $\begin{array}{l}\text { Higher } \\
\text { secondary }\end{array}$ & $118(85.5 \%)$ & $20(14.5 \%)$ & $138(100 \%)$ \\
\hline Graduation & $87(87 \%)$ & $13(13 \%)$ & $100(100 \%)$ \\
\hline Total & $605(78.1 \%)$ & $169(21.9 \%)$ & $774(100 \%)$ \\
\hline
\end{tabular}

When their knowledge was assessed regarding the identification of anaemia in a child using IMNCI guidelines, about $30.9 \%$ of the respondents correctly identified anaemia in child using standard IMNCI guidelines while $16.1 \%$ of the respondents believed that examination of eye is necessary and $41.3 \%$ believed the examination of blood is necessary to establish the diagnosis (Table 5). Statistically significant association seen between educational status of anganwadi workers and need for refresher course (Table 6).

\section{DISCUSSION}

In the present study $69.25 \%$ of anganwadi workers at anganwadi centers had their education level below higher secondary level. This could be the barrier to success of IMNCI program at any place. The study done by Sunder Gujaral et al shows that anganwadi workers educated up to higher secondary or above did well in supplementary nutrition, growth monitoring, vitamin A prophylaxis, health check-up, and immunization. ${ }^{5}$ In our study more than $40 \%$ of anganwadi workers were not aware regarding objectives of IMNCI training, this shows that during the work their vision is not clear; it could be due to low level of education.

Regarding the knowledge of assessing the serious illness, $80.7 \%$ of anganwadi workers were able to correctly classify the illness by recognizing the three clinical signs of serious illness (Table 3). Similar findings were obtained in a study done by united republic of Tanzania, ministry of health, which shows that $64 \%$ of community health workers correctly classified the severe category of illness in children. ${ }^{6}$

The correct assessment of dehydration by anganwadi workers was $45 \%$ in the study done by V. Kumar et al ${ }^{7}$ on assessment of the effect of training on management of acute diarrhea in primary health care setting, which is consistent with present findings The similar finding had obtained in the study carried out in Kenya by Jane $\mathbf{M}$ Kelly and Osama. ${ }^{8}$

When their knowledge was assessed regarding the problems of breast feeding, $67.31 \%$ of the respondents gave satisfactory answers and mentioned correctly about possible examination to be carried out (Table 3 ). This is consistent with findings of Dr. Gilbert Burnham which shows IMCI trained workers correctly asked for breast feeding problems in among $58 \%$ beneficiaries. ${ }^{9}$

When anganwadi workers were asked about diseases which could be prevented by immunization, $85.4 \%$ of respondents correctly answered all the six disease i.e. tuberculosis, polio, measles, diphtheria, whooping cough, tetanus (Table 4). Above findings are consistent with study done by Kapil U et al (Knowledge, attitude and practice of anganwadi workers with respect to immunization, growth monitoring \& supplementary nutrition. ${ }^{10}$

Regarding the knowledge of clinical features of pneumonia, in present study $62.9 \%$ of the respondents had correct knowledge (Table 5) while the study done in Kenya, shows $65.1 \%$ CHWs could correctly assess the clinical features of pneumonia during the first evaluation. ${ }^{8}$ It is evident that anganwadi workers should look for all the clinical features and signs because inadequate examination leads to wrong categorization and it leads to wrong treatment and adverse outcome (Table 5).

When their knowledge was assessed regarding the clinical features of malaria, nearly one third respondents i.e. $32.5 \%$ could be able to answer all the clinical features of malaria. Majority of them i.e. $56.8 \%$ believed that fever is the only presentation in case of malaria, therefore it must be clear from the above findings that even after the training majority of health workers' concepts regarding the presentation of malaria were not clear due to their routine mind-set.

In the present study $35.6 \%$ of the respondents believed that usage of growth chart were sufficient and minority of them believed that presence of pedal edema $(3.5 \%$ respondents) was sufficient to diagnose malnutrition in child (Table 5). As PEM is a great burden for India, this superficial knowledge could be less reliable.

When anganwadi workers knowledge was assessed regarding the identification of the malnutrition grade by using growth chart, $80.6 \%$ of the respondents correctly identify the grade IV of malnutrition while identification of low grade of malnutrition seems to be difficult by them (Table 5). The findings in our study are consistent with study of Kapil U et al. ${ }^{10}$ 
The study done by $\mathbf{J}$ Amaral et al in Brazil shows that health workers assessment task for weight checked against growth chart is $77.5 \%$ which is also consistent with our findings. ${ }^{11}$ The study Gilbert Burham shows that IMCI trained health workers checked children's weight against growth chart $82 \%$ of the times correctly then the non IMCI trained workers. ${ }^{9}$ The study done by D. Chattopadhyay (Knowledge and skills of anganwadi workers in Hoogly District West Bengal) shows that $60.9 \%$ of anganwadi workers had average skill regarding growth monitoring. ${ }^{12}$

Only $11.7 \%$ and $16.1 \%$ of the respondents knew that for the diagnosis of the anaemia, examination of tongue and eye are necessary respectively. This clearly showed lack of adequate knowledge even after training. Weber MW et al showed in his study that pallor of the conjunctiva, tongue, palm and nail beds was $66 \%$ sensitive and $68 \%$ specific. $^{13}$

\section{CONCLUSION}

From the present study it is evident that there are many lacunae in the knowledge of AWWs in the various perspective of IMNCI. For better implementation of IMNCI in the community following recommendations should be followed.

- For raising awareness in the community, health care workers at all levels should be well trained for knowledge and skill.

- To sustain the skill of AWWs for success of IMNCI program there is a need for refresher course within short time periods.

- There is also a need for supervising their work at field level frequently.

- Finally, community participation has a key role in successful implementation of any program which should not be overloaded.

Funding: No funding sources Conflict of interest: None declared

Ethical approval: Not required

\section{REFERENCES}

1. Report of an informal consultation on maintaining the performance of health workers trained in IMCI department of child and adolescent health and development. Geneva: WHO, 2001.

2. UNICEF IMNCI training modules for MO, module no.1 NEW DELHI 2005.
3. Child health programs in India -major milestones in child health available at http://mohfw.nic.in/dofwwebsite/childhealthrti.pdf. Accessed June 2009.

4. Synopsis, child health research project: validation of outpatient IMCI Guidelines January 1998 number 2.

5. Sunder Gujral, Rita Abbi, RajniMujoo, and Tara Gopaldas Determinants of community health workers' performance in India. Available at http://archive.unu.edu/unupressfood/8F134e/8F134 E03.

6. Integrated management of childhood illness: field test of the WHO/UNICEF training course in Arusha, United Republic of Tanzania Bulletin of the World Health Organization. 1997;75(1):55-64.

7. Kumar V, Kumar R, Khurana JL. Assessment of the effect of training on management of acute diarrhoea in a primary health care setting. J Diarrhoeal Dis Res. 1989;7(3-4):70-6.

8. Kelly JM , Osamba B, Garg RM, Hamel MJ, Lewis JJ, Rowe YS et al. Community Health Worker Performance In The Management Of Multiple Childhood Illnesses: Siaya District, Kenya. American Journal of Public Health. 2001;91(10):1617-24.

9. Burnham G. Impact of IMCI in Uganda, research to support house hold and community IMCI; report of meeting, Baltimore. Maryland, USA. J Health Popul Nutr. 2001;19(2):133-4.

10. Kapil U, Tandan BN. Current status monitoring research and evaluation system. Indian journal of public health. 1990;34:41-7.

11. Amaral J, Gouws E, Bryce J, Jorge A, Madeiro L, Ledo A. Effect of Integrated Management of Childhood Illness (IMCI) on health worker performance in Northeast-Brazil Cad. Saúde Pública. 2004;20(2):209-19.

12. Chattopadhyay D. A knowledge and skill of anganwadi workers in hoogly district, west Bengal. Indian journal of community medicine. 2004;29(3):117-8.

13. Weber MW, Mulholland EK. Evaluation of an algorithm for the integrated management of childhood illness in an area with seasonal malaria in the Gambia .WHO. 1996;75(1):25-32.

Cite this article as: Joshi KJ, Koringa HT, Sochaliya KM, Kartha GP. A study on knowledge regarding integrated management of neonatal and childhood illness among trained anganwadi workers of Surendranagar district, Gujarat, India. Int J Community Med Public Health 2016;3:581-5. 